\title{
Penetration of timolol eye drops into human aqueous humour
}

\author{
CALBERT I. PHILLIPS, ' R. SHAYLE BARTHOLOMEW,' GHULAMQADIR KAZI,' \\ CLAUDE J. SCHMITT, ${ }^{2}$ AND ROGER VOGEL ${ }^{3}$
}

From the 'Department of Ophthalmology, University of Edinburgh, and Princess Alexandra Eye Pavilion, Royal Infirmary, Edinburgh; ${ }^{2}$ Merck Sharp and Dohme Ltd (Chibret) Research Centre, Riom, France; and ${ }^{3}$ Merck Sharp and Dohme Ltd, Hertford Road, Hoddesdon, Hertfordshire

SUMMARY One to 7 hours after instillation of $0.5 \%$ timolol eye drops the aqueous humour aspirated from patients about to have cataract extraction showed concentrations of timolol ranging from $150 \mathrm{ng}$ per $100 \mathrm{mg}$ in the first 1 or 2 hours to $10 \mathrm{ng}$ per $100 \mathrm{mg}$ towards the end of the 7 hours. An exponential decay curve fitted the data well.

There is now ample evidence of the efficacy of timolol, a $\beta_{1}$ and $\beta_{2}$ adrenergic blocking agent, in lowering intraocular pressure in the short and long term and of its almost complete freedom from unwanted side effects in man. Accordingly it seemed of interest to find out the concentration of the drug in human aqueous humour at various times after instillation.

Previous studies relating to levels in aqueous humour of blocking agents have been done in albino rabbits either by measuring total radioactivity after instillation of labelled drugs ${ }^{1-4}$ or by assaying $\beta$ blockers by gas chromatography. ${ }^{1-5}$ These studies showed that timolol as well as other $\beta$ blocking agents readily penetrate into aqueous humour when topically applied in the rabbit's eye. Aqueous levels achieved after instillation of timolol were higher than those achieved after instillation of atenolol or metoprolol, ${ }^{3}$ whereas propranolol, practolol, oxprenolol, and alprenolol gave higher aqueous humour levels than timolol. ${ }^{5}$

The present paper deals with the measurement of levels of timolol achieved in aqueous humour after instillation of the drug in eye drops.

\section{Patients and methods}

Two drops of timolol $0.5 \%$ were instilled into the eyes of 20 patients before cataract extraction. The interval to operation was usually $2-3$ hours but the range was 1 to 7 hours.

Correspondence to Professor C. I. Phillips, Eye Pavilion, Chalmers Street, Edinburgh EH3 9HA.
At the beginning of the operation for cataract extraction a conjunctival flap was made, then a limbal groove. In some patients a tuberculin needle was used to perforate the deepest layers of the corneoscleral junction to allow aqueous to be aspirated; in others the incision was deepened into the anterior chamber for 1-2 mm at 12 o'clock, and aqueous was aspirated through a blunt Rycroft cannula. Each sample was stored in a small stoppered plastic tube at $-80^{\circ} \mathrm{C}$ or in dry ice during transport.

Most patients had general anaesthesia (halothane) preceded by diazepam (Valium) $10 \mathrm{mg}$. Some had local (including retrobulbar) anaesthesia. All had phenylephrine $10 \%$ eye drops preoperatively, and some had atropine $1 \%$ eye drops 24 hours and $1-2$ hours before operation.

\section{CHEMICAL ANALYSIS}

Standards were prepared with rabbit aqueous humour. As previously described, ${ }^{4}$ timolol assays were done by a gas chromatographic electron capture method after deriving the heptafluorobutyric ester (according to the procedure described by Tocco et $\left.a l .{ }^{6}\right)$ under the following conditions: $(a)$ temperature $200^{\circ} \mathrm{C}$ for the oven and $250^{\circ} \mathrm{C}$ for the injector and detector; $(b)$ carrier gas: argon/methane $(90: 10)$ with a flow rate of $55 \mathrm{ml} / \mathrm{min} ;(c) 1.1 \mathrm{~m}$ long $\times 3 \mathrm{~mm}$ internal diameter glass column containing $3 \%$ OV3 on 100-120 mesh Supelcon AWDMCS; (d) gas chromatograph Hewlett-Packard (model 5730) equipped with a $\left.{ }^{63} \mathrm{Ni}^{(15} \mathrm{mCi}\right)$ electron capture detector. 


\section{Results}

See Fig. 1. Levels of timolol in aqueous humour following instillation of 2 drops of timolol eye drops $0.5 \%(500 \mu \mathrm{g}$ per $100 \mathrm{mg}$ ) ranged from about $150 \mathrm{ng}$ per $100 \mathrm{mg}$ in the first 1 or 2 hours to $10 \mathrm{ng}$ per $100 \mathrm{mg}$ towards the end of 7 hours. The concentration in aqueous is thus of the order of $1 / 5000$ th of that in the eye drops.

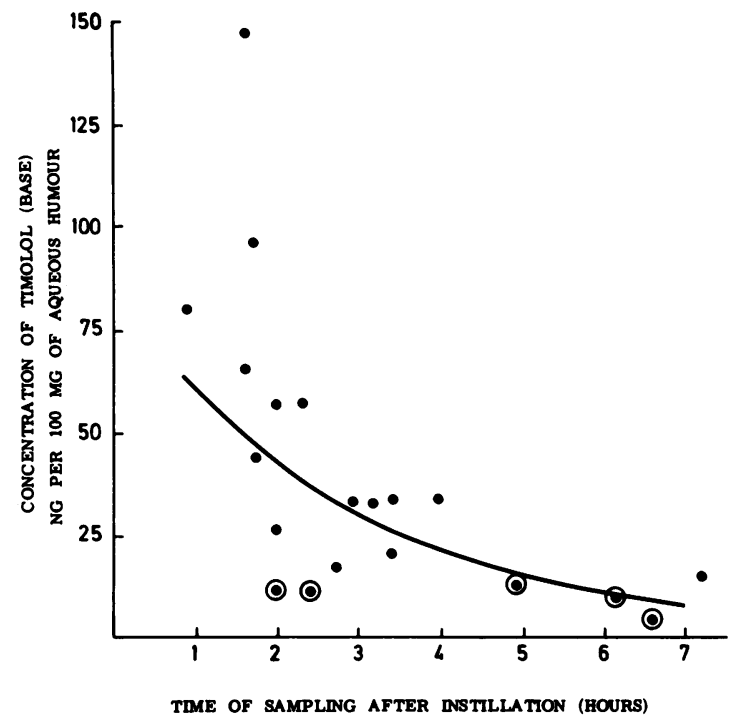

Fig. 1 Gas chromatographic assay of timolol in human aqueous humour. $\bullet=$ Experimental value. $\bigcirc=$ Experimental value calculated by extrapolation because the concentration was just below the limit of sensitivity. Computed curve $C=86 \cdot 06 e^{-0.0058 t} . r=0 \cdot 7075, p<0 \cdot 001$.

A few values are marked $O$ in the graph because, as a result of the low volume of available aqueous humour, the measured amount of timolol in the sample was low and out of the limits of perfect linearity of the standard curve established with rabbit aqueous humour. However, these values are very close to the lower limit, so that they can be considered as valid when calculated by extrapolation of the standard curve. When all values are included, there was a significant relationship between the logarithm of the concentration of timolol and the time of sampling $(r=0.7075, p<0.001)$. The decrease in concentration can be expressed as $c=86.06 \mathrm{e}^{-0058 t}$ where $\mathrm{c}$ is timolol concentration in $\mathrm{ng}$ per $100 \mathrm{mg}$ aqueous humour and $t$ is time after instillation in minutes. The exclusion of the points marked $\bigcirc$ does not greatly alter the relationship $\left(c=93 \cdot 37 \mathrm{e}^{-0 \cdot 0050 t}\right.$, $r=0.6956, p<0 \cdot 01$ ).

\section{Discussion}

The values in human aqueous humour 1-2 hours after instillation of eye drops are slightly lower than similar ones in a series of rabbits given $0.5 \%$ timolol eye drops at the same time interval: at a 7-hour interval these values in man are about 10 times the level in rabbits (C. J. Schmitt, unpublished data). Presumably the turnover rate of aqueous humour in elderly cataract patients is much less than in young rabbits. Also, timolol may penetrate into a rabbit's aqueous more easily than into a human's because of the rabbit's thinner corneoscleral envelope. In animals Krupin et al. ${ }^{7}$ demonstrated a reduction in aqueous secretion by halothane, which may also have similarly affected our patients. Values in patients with openangle glaucoma would probably be higher than in our (nonglaucomatous) patients because of reduced rate of outflow.

Previous studies in rabbits using ${ }^{14} \mathrm{C}$-labelled $\beta$ blockers showed that, after instillation of a $0.5 \%$ solution of timolol, the total radioactivity in aqueous humour reached a peak of concentration between 30 minutes and 60 minutes. The level of timolol equivalent to total radioactivity at peak time was 300 to $600 \mathrm{ng}$ per $100 \mathrm{mg} \cdot{ }^{1-3}$ At the peak time of timolol, the aqueous humour level of this drug was higher than those achieved after instillation of a more concentrated solution of atenolol, metroprolol, and propranolol. ${ }^{3}$ However, it must be noticed that for shorter times (10-15 min) aqueous humour levels of radioactivity induced by instillation of propranolol $(0.5 \%$ and $1 \%)$ were higher (250 to $500 \mathrm{ng}$ per 100 $\mathrm{mg}$ ) than those induced by instillation of timolol $0.5 \%$ (150 to $300 \mathrm{ng}$ per $100 \mathrm{mg}$ ), indicating a more rapid ocular penetration of the former. ${ }^{3-7}$

The method of removal of our aqueous specimens may result in some dilution of aqueous with serum (or occasionally a very little blood), so that any value may well be a slight underestimate. Similarly the manipulations of the eye for the few minutes at the beginning of the operation and also the anaesthetic (local or general) and the general state of the patient-for example, calm or excited-may have altered the dynamics of aqueous humour.

Many more specimens would have to be included to allow a satisfactory mean and standard deviation to be obtained at each interval, but we judge that to be of little value.

Fundamentally, the exponential decay curve calculated from our results (see Fig. 1) is presumably the resultant of many influences - turnover rate of aqueous humour, tissue uptake, and diffusion or bulk flow of aqueous humour beyond the anterior chamber.

This method of using patients having intraocular operations for an unrelated condition provides a 
useful and probably the only means of collecting data on drug penetration into the aqueous in man as opposed to animals.

\section{References}

1 Merck Sharp and Dohme Research Laboratories, USA, and MSD Chibret Research Institute, France. Timolol maleate ophthalmic solutions: preclinical evaluation. 9 January 1978.

2 Ros FE, Innemee HC, Van Zwieten PA. Penetration of atenolol in the rabbit eye. Albrecht von Graefes Arch Klin Ophthalmol 1978; 208: $235-40$.

3 Ros FE, Innemee HC, Van Zwieten PA. Ocular penetration of $\beta$-adrenergic blocking agents. An experimental study with atenolol, metoprolol, timolol and propranolol. Doc Ophthalmol 1979; 48: 291-301.

4 Schmitt CJ, Lotti VJ, Le Douarec JC. Penetration of timolol into the rabbit eye. Measurements after ocular instillation and intravenous injection. Arch Ophthalmol 1980; 98: 547-51.

5 Schmitt CJ, Lotti VJ, Le Douarec JC. Measurement of the aqueous humour and serum levels of five $\beta$ blocking agents after ocular instillation to the rabbit. 1980 (in preparation).

6 Tocco DJ, de Luna FA. Duncan AEW. Electron capture determination of timolol in human plasma and urine. J Pharm Sci 1975; 64: $1879-81$.

7 Krupin T, Feilt M, Roshe R, Lee S, Becker B. Halothane anaesthesia and aqueous humour dynamics in laboratory animals. Invest Ophthalmol Visual Sci 1980; 19: 519-21. 